\title{
Liquid Biphase Systems Formed in Ternary Mixtures of Two Organic Solvents and Ethylene Oxide Oligomers or Polymers
}

\author{
Marcos Spitzer, Luís H.M. da Silva and Watson Loh*
}

\author{
Instituto de Química, Universidade Estadual de Campinas, CP 6154, 13083-970, Campinas - SP, Brazil
}

\begin{abstract}
Este trabalho descreve estudos sobre o equilíbrio líquido-líquido em sistemas ternários contendo polímeros ou oligômeros de óxido de etileno, heptano e um de três diferentes solventes orgânicos (metanol, clorofórmio ou diclorometano). Os efeitos da temperatura, da massa molar do polímero e da natureza química do solvente polar sobre o equilíbrio de fase foram investigados. Para todos os sistemas, a região de miscibilidade diminuiu à medida que a temperatura era reduzida, indicando que o processo de separação de fases é exotérmico. Tanto para misturas binárias quanto ternárias, a miscibilidade também diminuía quando aumentava o tamanho da macromolécula, ainda que este efeito tenha sido bem menos significativo em sistemas ternários. Estas características sugerem que o processo de separação de fases nestes sistemas ternários seja mais afetado por contribuições entálpicas do que entrópicas. Com relação aos diferentes solventes polares usados, a menor região de miscibilidade foi verificada com metanol, em concordância com sua menor capacidade de solubilização de PEO. A maior miscibilidade foi verificada com clorofórmio, não muito diferente da observada com diclorometano. As linhas de amarração foram determinadas para alguns sistemas, confirmando a forte segregação entre o polímero e o heptano.
\end{abstract}

Phase equilibrium data were determined for ternary systems containing ethylene oxide oligomers or polymers, heptane and one of three organic solvents (methanol, dichloromethane or chloroform). The effects of temperature, of polymer molecular weight and of the chemical nature of the organic solvent on phase equilibrium were investigated. For all the studied systems, the miscibility region was reduced as temperature decreased, indicating an exothermic phase separation process. For both binary and ternary mixtures, the miscibility also decreased as the macromolecule size increased, although this effect was less significant for the ternary mixtures. These features suggest that phase separation is more influenced by enthalpic than entropic contributions. Regarding the different polar solvents investigated, methanol presented a much smaller miscibility region, in accordance with its inferior solvation ability for PEO. The largest miscibility region was observed with chloroform, not much different from the behaviour observed with dichloromethane. Tie lines were determined for some systems, confirming the strong segregation between polymer and the hydrocarbon solvent.

Keywords: poly(ethylene oxide), liquid-liquid equilibria, polymer solutions, preferential solvation

\section{Introduction}

Liquid biphase systems possess great importance owing to their potential use in extraction processes, with applications in many fields. These vary from environmental applications (for extraction and/or analysis of pollutants, either organic compounds or metals), purification of biomolecules (an area where aqueous two-phase systems have shown great potential ${ }^{1,2}$ ) or catalysis. Regarding this last subject, great importance is being now devoted to the development of more environmentally friendly processes, including the design of water soluble catalysts ${ }^{3}$, of alterna-

e-mail: wloh@iqm.unicamp.br tive biphase systems, for instance those with fluorinated compounds ${ }^{4}$, or the use of ionic liquids as reaction medium ${ }^{5}$.

We have recently reported investigations on a liquid biphase system formed by the addition of polyethylene oxide (PEO) to a homogenous mixture of heptane and dichloromethane ${ }^{6}$. This system has additionally provided an easy and efficient way to catalyst recycling and product recovery for a variety of catalytic processes ${ }^{7}$. This approach presents many advantages, namely: absence of water, possibility of easy interchange between homogeneous and biphase regions by either composition or temperature changes, use of common reagents and flexibility to allow tailoring to different purposes and to a wide range of reactions. 
Polymer solutions in mixed solvents are very common in many applications, one of the reasons being the capability of tuning the solubilisation power of the mixture by composition changes. In addition, phase separation in these polymer solutions is a topic that has received much attention due to its importance in polymer processing (especially if considering that most polymeric blends conform to the same phenomena), polymer fractionation ${ }^{8}$ and, more recently, particularly owing to alternative procedures for membrane formation ${ }^{9-11}$. Efforts related to this topic range from compilation of phase equilibrium data (binodal curves and tie lines) for specific systems to the development of theories with modelling and predicting capability.

Formation of liquid biphase systems in mixtures containing polyethylene oxides are more common in aqueous solutions, where its mixture with dextran or some electrolytes produce the already mentioned aqueous two-phase systems, which are subject of many investigations for their potential use in bioseparation processes ${ }^{1,2}$. Other liquid biphase systems have been reported to occur in mixtures of some PEO/tetrahydrofuran/water ${ }^{12}$ and PEO 6000/cyclohexane/methanol ${ }^{13}$.

The recognition of the importance of these biphase systems and the relative lack of data on phase equilibria in these ternary mixtures have prompted this investigation. It aims at a systematic evaluation on how factors as the chemical nature of the components, temperature and the polymer molecular weight affect their phase behaviour. In this respect, the identification of appropriate conditions to the formation of these two-phase systems is important to widen their applications. Moreover, we believe that such data may help in understanding the mechanism underlying the formation of these biphase systems.

\section{Experimental}

\section{Materials}

The ethylene oxide oligomers and polymers used were: diethylene glycol, PEO 200 and PEO 1000, from Aldrich, and PEO 3350 and PEO 10000, from Sigma. The liquid compounds were treated with activated molecular sieves and the solid ones were kept in a desiccator under $\mathrm{P}_{2} \mathrm{O}_{5}$ for at least five days.

Dichloromethane (p.a., Aldrich) was treated by refluxing over $\mathrm{CaCl}_{2}$ for $24 \mathrm{~h}$ and distilled under nitrogen. Chloroform (p.a., Aldrich) was washed with water, dried with $\mathrm{K}_{2} \mathrm{CO}_{3}$ and refluxed with $\mathrm{P}_{2} \mathrm{O}_{5}$ and $\mathrm{CaCl}_{2}$, being then distilled. Methanol (p.a., Aldrich) was refluxed with activated $\mathrm{CaO}$ for $48 \mathrm{~h}$, filtered and distilled with $\mathrm{Mg} / \mathrm{I}_{2}$. n-Heptane, Carlo Erba and Sigma, p.a., was dried with molecular sieves. After treatment, all solvents were kept over activated molecular sieves.

\section{Cloudpointmeasurements}

PEO 3350 solutions were cooled with a dry ice/acetone mixture below its cloud point, being kept for at least $15 \mathrm{~min}$. After that, they were warmed under stirring, at a rate slower than 1 degree min $^{-1}$, until visual detection of complete homogeneity. These measurements were repeated, at least, five times for each solution. For some solutions, their cloud points were determined by detecting the appearance of turbidity upon cooling, producing essentially the same results.

\section{Determination of phase diagrams}

Portions of the ternary phase diagram were determined by titrating a PEO solution in the polar solvent with heptane under visual inspection, in a temperature controlled environment (within 1 degree for experiments at $-50^{\circ} \mathrm{C}$ and within 0.1 degree for the other temperatures). Phase separation was indicated by persistent turbidity, and care was taken to ensure that polymer solutions be allowed to equilibrate after each dilution. Each phase diagram includes data from at least two independent experiments, which are not distinguishable. Considering the narrow molecular weight distribution of these PEO samples, these curves were assumed to be close the true binodals.

\section{Tie-line analyses}

The biphase systems were left, for over $48 \mathrm{~h}$ at $25^{\circ} \mathrm{C}$, which was followed by careful separation of the phases. They were weighed and aliquots were directed to gas chromatography (GC) and dry weight measurement. Heptane content was determined by GC in an HP 5890 chromatograph, using nitrogen as carrier gas, FID detector and ciclooctane as internal standard. The polymer content was assayed by its dry weight, removing the solvents at $60^{\circ} \mathrm{C}$. Both methods were tested with standard samples attesting their accuracy. Dichloromethane concentration was calculated by difference. The mass balance for polymer and heptane contents produced deviations smaller than $2 \%$.

\section{Measurements of polymer solubility}

At least three PEO saturated solutions in each polar organic solvent were left with occasional stirring at $25^{\circ} \mathrm{C}$ and aliquots were extracted after 25, 30 and 35 days. The polymer content in these aliquots was determined by dry weight $\left(60^{\circ} \mathrm{C}\right.$ for $\left.5 \mathrm{~h}\right)$, producing essentially the same results regardeless the time of collection, assuring that equilibrium has been achieved. 


\section{Results and Discussion}

\section{Effect of temperature and polymermolecularweight onphase equilibria}

The effect of temperature on the solubility of these macromolecules in methanol, dichloromethane and chloroform was investigated by determination of their solution cloud points. The results are shown in Figure 1 for PEO 3350 and reveal that all these binary systems present a UCST (upper critical solution temperature) behaviour, opposite to the one observed for their aqueous solutions, for which phase separation was found to occur as temperature increases (LCST type $)^{14,15}$. As for other polymer solutions with UCST behaviour, polymer phase separation should be exothermic, associated to a favourable enthalpic contribution which may arise from the energetic balance between polymer-polymer interaction and (polymer solvation + solvent/solvent interaction) ${ }^{15}$, the former being greater (more negative). The molecular weight dependence of their cloud points, shown in Figure 2 for chloroform solutions (essentially the same features are observed for the other solvents), conforms to the trend that larger polymers are more prone to phase separation, in accordance with the behaviour predicted from contribution of configurational entropy ${ }^{16}$.

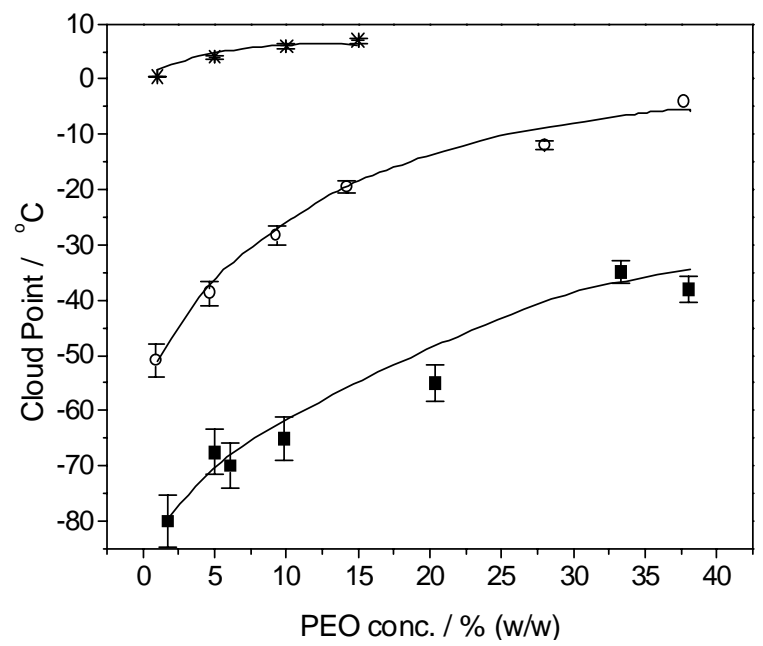

Figure 1. Effect of temperature on the solubility of PEO 3350 in: (*) methanol, (○) chloroform and (ם) dichloromethane.

Afterwards, temperature effect on phase equilibria of ternary systems containing PEO 200, 1000, 3350 and 10000, and two polar solvents, $\mathrm{CH}_{2} \mathrm{Cl}_{2}$ and $\mathrm{CHCl}_{3}$ was investigated and the most important results are summarised in Figure 3, for temperatures ranging from -50 to $25^{\circ} \mathrm{C}$ (for ternary systems containing chloroform, polymer precipitation was verified at temperatures lower than $-15^{\circ} \mathrm{C}$, and with methanol, this occurred below $10{ }^{\circ} \mathrm{C}$ ). For the sake of

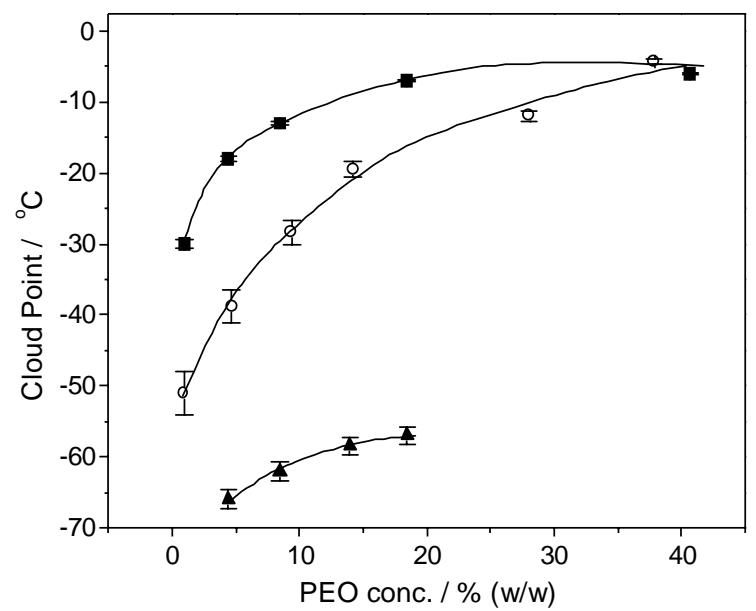

Figure 2. Dependence of the cloud points of PEO solutions in chloroform with the polymer molecular weight: (A) PEO 200, (O) PEO 3350 and (ם) PEO 10000.

comparison among different polymers, their composition is expressed in terms of monomer mole fraction. Analysing these figures, it is possible to confirm that phase separation is favoured as temperature decreases, in accordance with the previous findings on binary mixtures, also indicating an exothermic process (favourable enthalpic contribution to phase separation). A similar temperature dependence was reported by Wolf and Willms when analysing the phenomenon of cononsolvency in mixtures of polystyrene/cyclohexane/ $\mathrm{DMF}^{17}$. Presently determined temperature effects on phase separation in ternary systems, however, are small and seem to be larger for systems containing dichloromethane.

The configurational entropy contribution to phase equilibria may be assessed by comparison of phase diagrams with oligomers and polymers of different molar weights, as, for instance, represented in Figure 4. For all the other combinations investigated, only minor variations were observed with increasing molecular weights, and they were more prominent in the region diluted in polymer. For diethylene glycol, however, a significantly different behaviour was verified, with a larger biphasic region. As this compound may not be classed exactly as an ethylene oxide oligomer, it is not possible to ascribe whether such a different phase diagram arises from its smaller molecular weight or from other factors as, for instance, a more relevant relative contribution from its hydroxyl end groups in comparison with larger polyethylene oxides, as already observed by Wolf et al. in similar investigations ${ }^{18}$.

These results point out that temperature and the polymer molecular weight are important in affecting phase behaviour of binary mixtures, but, comparing ternary mixtures with binary ones, temperature influence on the phase equilibria is less important, and that of polymer size is even smaller. Moreover, as temperature decreases, this molecular weight effect tends to 

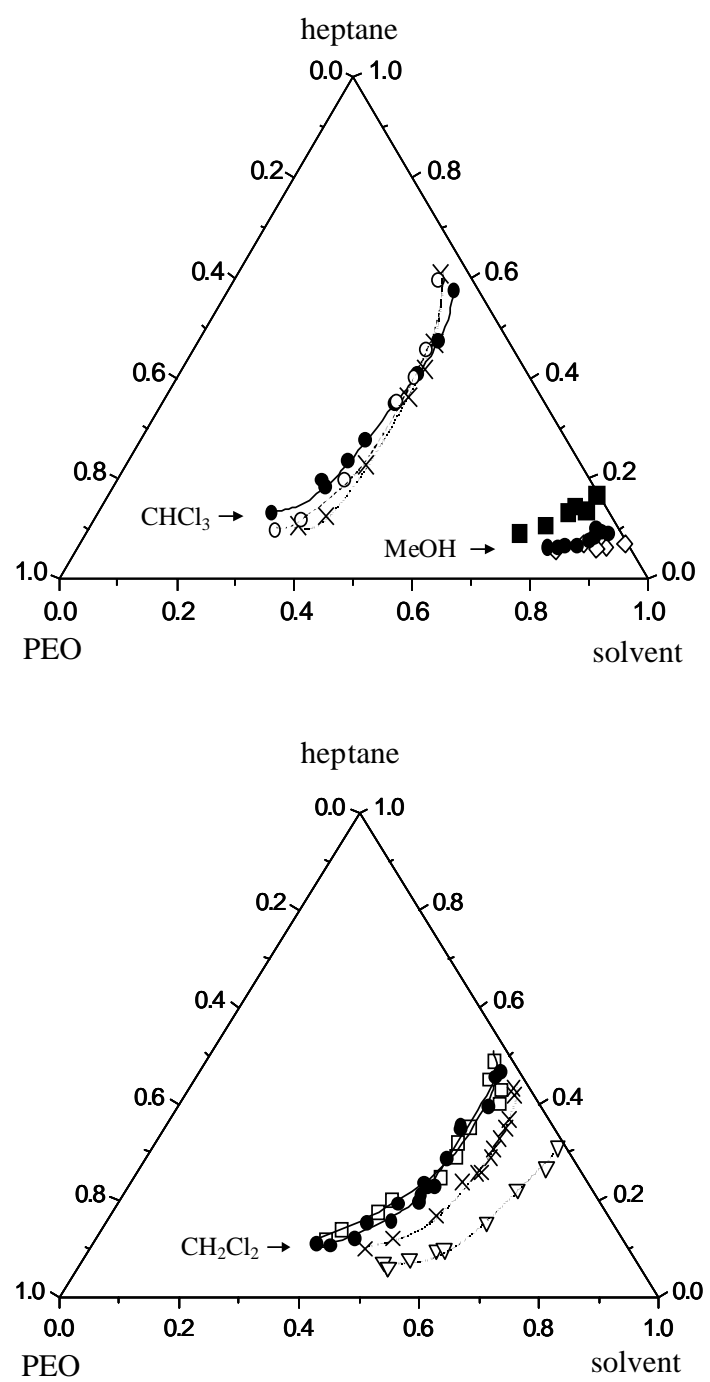

Figure 3. Temperature effect on phase equilibria of ternary systems containing PEO 3350, heptane and $\mathrm{CH}_{2} \mathrm{Cl}_{2}, \mathrm{CHCl}_{3}$ or $\mathrm{CH}_{3} \mathrm{OH}$ (solvent indicated in the diagrams). Temperatures: $50{ }^{\circ} \mathrm{C}(\square), 25^{\circ} \mathrm{C}$ (○), $10^{\circ} \mathrm{C}(\diamond), 0^{\circ} \mathrm{C}(\bigcirc),-15^{\circ} \mathrm{C}(\times)$ and $-50{ }^{\circ} \mathrm{C}(\nabla)$. All compositions are expressed on the basis of $\mathrm{mol} \%$ and, for PEO, mol refers to moles of monomer units.

vanishing. Interestingly, these features are completely different from those reported for aqueous two-phase systems (ATPS) containing PEO, for which phase separation was found to depend strongly on temperature and on polymer molecular weight 2. Such findings point out that, although ATPS formation be also associated to the presence of a good solvent for PEO (water) and to segregation between PEO and the other component, their mechanism of formation should be rather different.

\section{Comparison of phase diagrams with different polar solvents and phase composition analysis}

These phase diagrams may be alternatively analysed in terms of contributions from the chemical nature of the

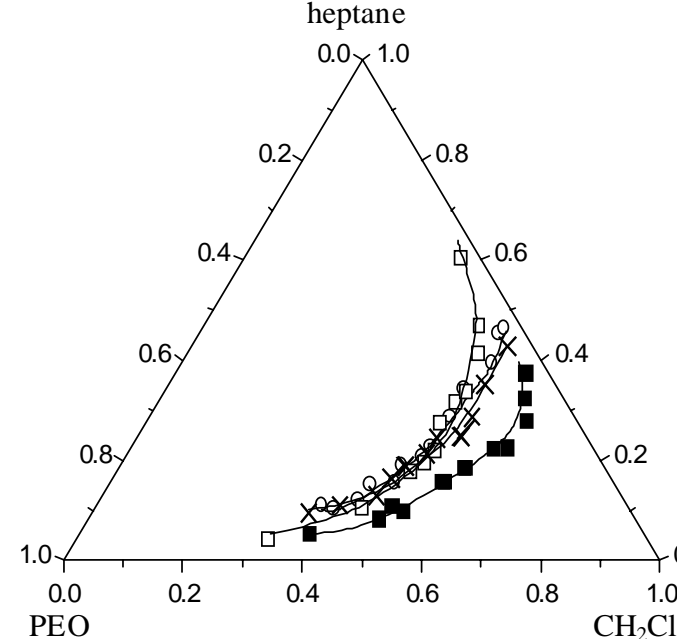

Figure 4. Phase equilibrium dependence on the polymer/oligomer molecular weight for ternary systems ( $\mathrm{PEO}+\mathrm{CH}_{2} \mathrm{Cl}_{2}+$ heptane),

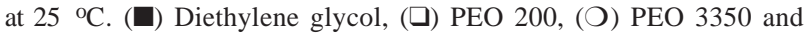
(X) PEO10000. All compositions are expressed on the basis of mol\% and, for PEO, mol refers to moles of monomer units.

polar organic solvent employed (chloroform, dichloromethane or methanol), as exemplified by Figure 3. It is clear from these data that the two-phase region is larger with methanol, followed by dichloromethane and chloroform. The polar solvent efficacy in enabling the system miscibility, therefore, follows the opposite sequence. Considering that PEO has low affinity by hydrocarbons, one possible explanation for this sequence would be related to the intensity of interaction between this polar solvent and the macromolecule.

For this reason, the solubility of PEO 3350 , at $25^{\circ} \mathrm{C}$, in these three polar solvents was measured and the results were: $63( \pm 5) \%(\mathrm{w} / \mathrm{w})$ in dichloromethane, $51( \pm 1) \%$ in chloroform and $33( \pm 2) \%$ in methanol (the standard deviations among the replicates are shown in parenthesis). This solubility trend agrees with the observation of the largest biphasic region with methanol, but does not explain the observed sequence for the other two solvents. Another approach used to interpret solubilities is the one represented by Hildebrand parameter, which has also been applied to polymer solutions ${ }^{19}$. According to this approach, miscibility will be enhanced for components with closer solubility parameters, which are calculated based upon their cohesive energies. The literature solubility parameter for PEO is $19-20 \mathrm{MPa}^{1 / 2} 19$, whereas for the polar solvents, these values are: 18.8 for chloroform, 20.0 for dichloromethane, and 29.7 for methanol. Analysis of these values may explain the lower polymer solubility in methanol, but does not help distinguishing between the solvation capacity of dichloromethane and chloroform, since their solubility parameters are similarly close to that of 
PEO. Therefore other factors must be used to account for these more complex phenomena underlying phase equilibria in these binary and ternary mixtures.

Regarding ternary mixtures the origin for this incomplete explanation may arise from the other interactions occurring in these systems. A thorough analysis of phase equilibria in these ternary systems would have to take into account the three binary interactions, as, for instance, described by Wolf using the framework of Flory-Huggins theor ${ }^{20}$. Moreover, effects like preferential solvation of the polymer by one of the low-molecular weight components are likely to occur (as, for instance, reported in references 21 and 22), especially considering the dissimilarity in solvent quality for PEO.

Ethylene oxide oligomers and polymers are almost insoluble in heptane (less than $0.2 \%$, by weight), what should rule out contributions from any interaction between them. The interaction between polymer and the polar solvent was previously appraised, leaving the contribution of the interaction between the two organic solvents to be assessed. The interplay of these interactions could be discerned by analysis of the compositions of the phases in equilibrium or, in other words, by determining the system tie lines.

Tie line analyses were performed by determining phases compositions for the systems PEO $10000 / \mathrm{CH}_{2} \mathrm{Cl}_{2} /$ heptane and PEO $10000 / \mathrm{CHCl}_{3} /$ heptane and the results are shown in Figure 5. A close agreement was observed for the phase boundaries determined via turbidimetric titration and from the tie lines analyses, confirming the accuracy of both methodologies employed. Also, the segregation between the polar ethylene oxide polymer and the apolar hydrocarbon solvent was confirmed, the bottom phase being richer in PEO. With this respect, almost no polymer could be measured in the upper (heptanerich) phase, whereas a small, but significant, amount of heptane was found in the bottom phase. This indicates that heptane partitioning bears some contribution from its interaction with the polar solvent but, on the other hand, even the presence of some polar solvent in the upper phase is not capable of allowing polymer solubilisation. More polymer is found in the heptanerich phase when chloroform is present, in comparison with dichloromethane, confirming the greater ability of the former in ensuring miscibility, as already verified for the larger homogeneous area observed with this polar solvent. The partitioning of the polar solvent between both phases should represent a balance between its interaction with PEO and with heptane.

If any of the binary interactions was prevalent in determining phase equilibrium compositions, a correlation between amounts of the interacting components was
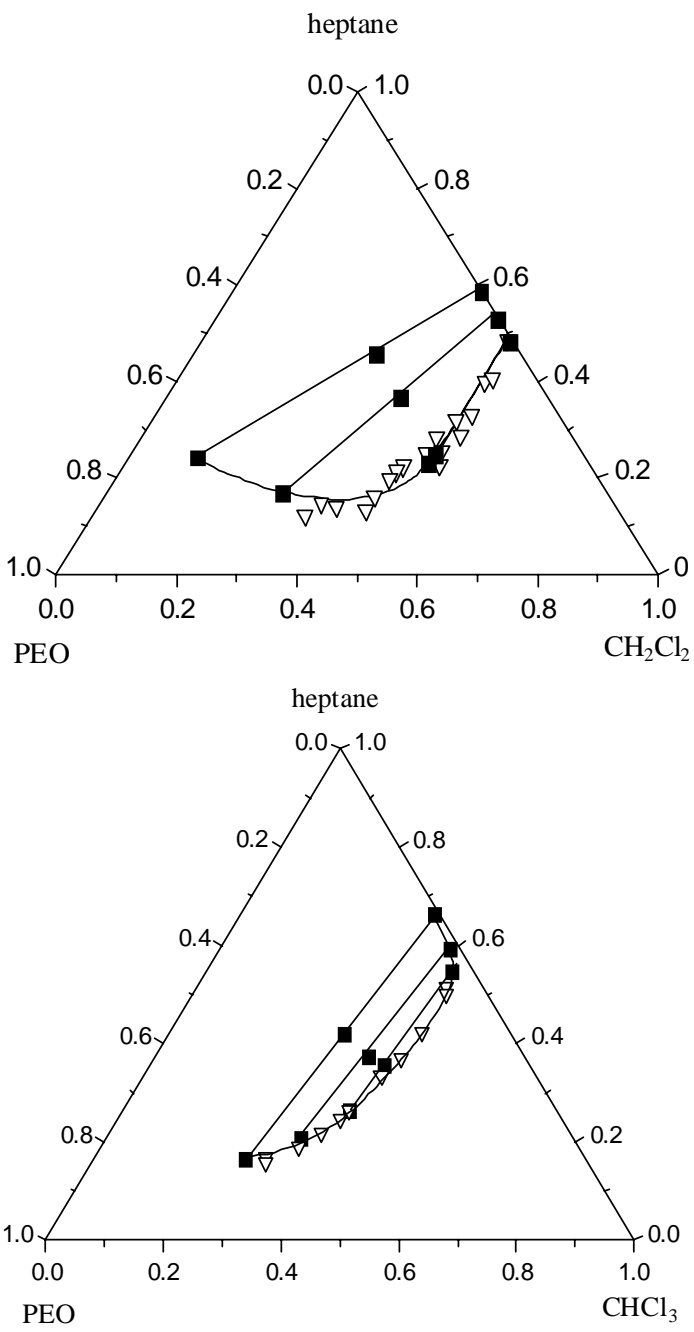

Figure 5. Tie line analyses for the systems PEO $10000+$ heptane + $\left(\mathrm{CH}_{2} \mathrm{Cl}_{2}\right.$ of $\left.\mathrm{CHCl}_{3}\right)(\square)$. Phase boundaries determined by turbidimetric titration are also indicated $(\nabla)$. All compositions are expressed on the basis of mol\% and, for PEO, mol refers to moles of monomer units.

expected to be found. In order to investigate whether this was the case, the ratios between the number of moles for all the components in both phases were calculated (not shown), but no trend could be verified. This lack of correlation, however, does not rule out the existence of important contributions arising from other interactions than polymer solvation.

In summary, regarding the effect of the polar solvent chemical nature on the ternary system miscibility, it is possible to explain why ternary systems containing methanol present minor miscibility owing to its inferior solvation capacity for PEO. However, the greater miscibility region of ternary systems containing chloroform, in relation to the one with dichloromethane, does not conform to the same pattern. For these systems, other interactions involving the two organic solvents must be taken into account to explain the observed trend. 


\section{Conclusions}

This work described liquid-liquid equilibrium in a ternary mixture containing PEO and two organic solvents. Phase diagrams were determined, providing important data to support application of these systems in a variety of extraction processes. Moreover, the effect of some parameters on phase equilibria was investigated and, in summary, the results indicate that phase separation in ternary mixtures is only slightly affected by temperature and polymer molecular weight. The chemical nature of the polar solvent, however, was very important in determining the extent of miscibility for this mixture, this being larger with chloroform, followed by dichloromethane and methanol. In some sense, these phase equilibria resemble more features of mixtures of low-molecular weight compounds than polymer solutions. No simple explanation for this trend could be found, indicating a more complex interplay among the binary interactions, perhaps associated to phenomena like preferential polymer solvation.

\section{Acknowledgements}

The authors acknowledge the Brazilian Agencies FAPESP and CNPq for financial support to this project in the form of grants to M.S. and W.L. L.H.M.S. thanks Universidade Federal de Viçosa for a leave of absence and CAPES-PICDT for a doctoral scholarship. R. Buffon is also gratefully acknowledged for the use of the gas chromatograph.

\section{Electronic supplementary information}

Includes phase diagrams for ternary mixtures of poly(ethylene oxide) of different molecular weights + heptane + polar organic solvent (dichloromethane, chloroform or methanol). Contains also examples of temperature effects on these phase equilibria. Available at: http://www.sbq.or.br/jbcs/2000/vol11_n4/indice.

\section{References}

1. Albertsson, P. A. Partition of Cell Particles and Macromolecules; Wiley-Interscience; New York, 3rd ed. 1986.

2. Zaslavsky, B. Y. Aqueous Two-Fase Partioning: Physical Chemistry and Bionalitical Applications; Marcel Dekker; New York, 1995.

3. Bergbreiter, D. E. Catal. Today 1998, 42, 389.

4. Horváth, I. T. Acc. Chem. Res. 1998, 31, 641.

5. Dullius, J. E. L.; Suarez, P. A. Z.; Einloft, S.; de Souza, R. F.; Dupont, J.; Fischer, J.; de Cian, A. Organometallics 1998, 17, 815.

6. Silva, L. H. M.; Loh, W. Chem. Commun. 1998, 787.

7. Da Rosa, R. G.; Martinelli, L.; Silva, L. H. M.; Loh, W. Chem. Commun. 2000, 33.

8. Wolf, B. A. Adv. Mater. 1994, 6, 701.

9. Maggioni, J. F.; Nunes, S. P.; Pires, A. T. N.; Eich, A.; Horst, R.; Wolf, B. A. Polymer 1998, 39, 5133.

10. Cheng, L. P. Macromolecules 1999, 32, 6688.

11. Boom, R. M.; Van Den Boomgaard, T.; Smolders, C. A. Macromolecules 1994, 27, 2034.

12. Park, I. H.; Kim, M. J. Macromolecules 1997, 30, 3849.

13. Staikos, G.; Donods, A. Phys. Rev. A 1986, 33, 4479.

14. Silva, R. C.; Loh, W. J. Colloid Interface Sci. 1998, 202, 385.

15. Silva, R. C.; Spitzer, M.; Silva, L. H. M.; Loh, W. Thermochim. Acta 1999, 328, 161.

16. Flory, P. J. Principles of Polymer Chemistry; Cornell University Press; Ithaca; 1953.

17. Wolf, B. A.; Willms, M. M. Makromol. Chem. 1978, 179, 2265.

18. Wolf, B.A.; Schuch, W. Makromol. Chem. 1981, 182, 1801.

19. Barton, A.F.M. Handbook of Solubility Parameters and Other Cohesion Parameters; CRC Press; Florida, 1988.

20. Wolf, B. A. Pure Appl. Chem. 1985, 57, 323.

21. Chetan, A. K.; Pavlova, Y.; Green, M. M.; Morawetz, H. J. Am. Chem. Soc. 1997, 119, 6991.

22. Müller-Plathe, F.; van Gunsteren, W. F. Polymer 1997, $38,2259$.

Received: February 17, 2000

FAPESP helped in meeting the publication costs of this article. 